\title{
CORRIGENDUM
}

\section{Effect of diabetes and metabolic syndrome on myocardial mechano-energetic efficiency in hypertensive patients. The Campania Salute Network}

C Mancusi, MA Losi, R Izzo, G Canciello, MV Manzi, A Sforza, N De Luca, B Trimarco and G de Simone

Journal of Human Hypertension (2017) 31, 424; doi:10.1038/jhh.2017.3

Correction to: Journal of Human Hypertension (2017) 31, 395-399; doi:10.1038/jhh.2016.88; published online 29 December 2016

Since the online publication of this article the authors realised there were errors in Figures 1 and 2.

In Figure 1, the scale on the $Y$-axis was incorrect. An amended version of Figure 1 can be seen below.
Furthermore, there was an error in the legend provided for Figure 2. The legend was initially published as 'Relation between $\mathrm{MVO}_{2}$ and stroke work in the presence of insulin resistance. MEEi, Myocardial energetical efficiency indexed for $397 \mathrm{~g}$ of LV mass, $\mathrm{MVO}_{2}$, oxygen consumption.' This should have been published as 'Relation between $\mathrm{MVO}_{2}$ and stroke work in the presence of insulin resistance. MEEi, myocardial energetical efficiency indexed for $\mathrm{g}$ of LV mass; $\mathrm{MVO}_{2}$, oxygen consumption.'

The authors would like to apologise for any inconvenience caused by these errors.

These errors have now been rectified, and the corrected article appears in this issue. The html and online pdf versions have also been rectified, and now carry the corrected paper.

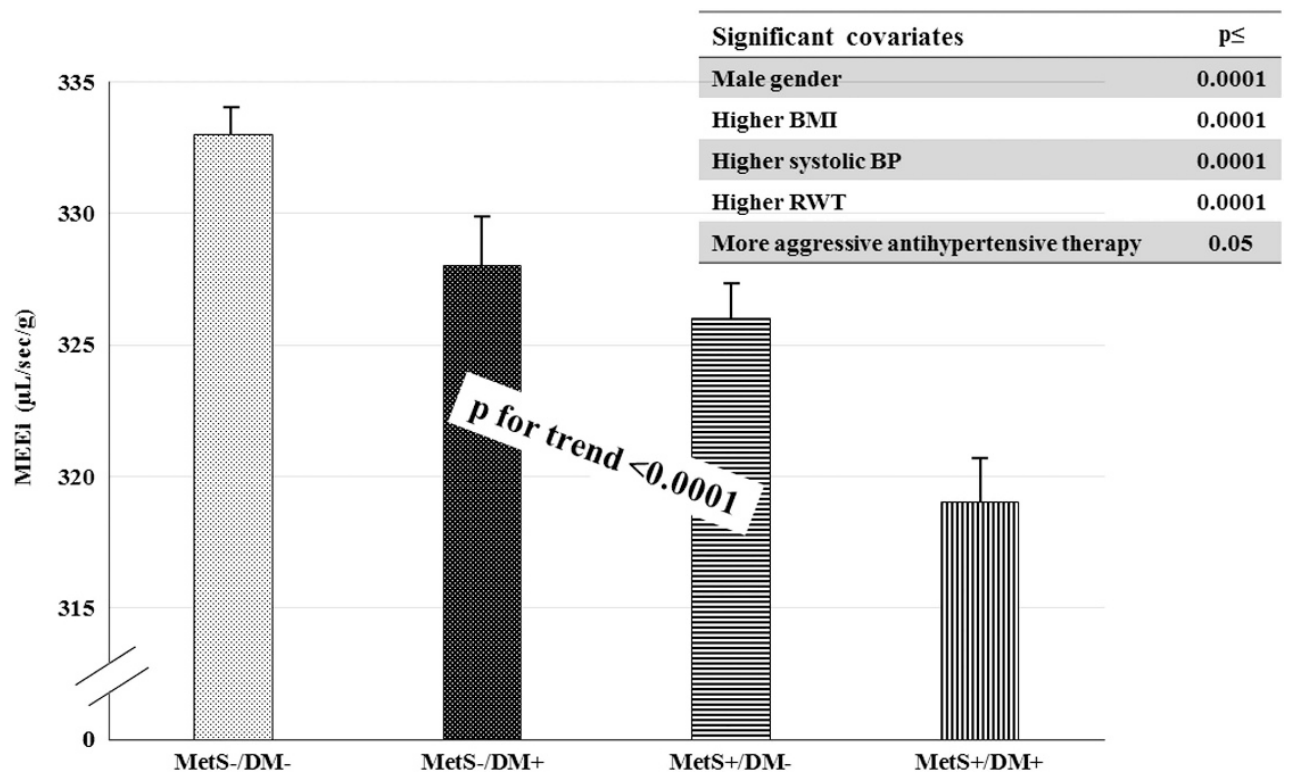

Figure 1 